\title{
NINGÚN LUGAR SAGRADO: DERROTA, VIOLENCIA Y ESCRITURA EN ROBERTO BOLAÑO
}

\author{
POR \\ Paula Aguilar \\ Universidad Autónoma de Entre Ríos - CONICET
}

En un riguroso estudio imprescindible para la discusión por las memorias del pasado reciente argentino, Hugo Vezzetti (2009) explora la cultura revolucionaria de la violencia para desandar los clisés que han fraguado una "visión pacificada de la militancia" (100) y recuperar la experiencia de la lucha armada a partir de sus narrativas, su estructura de sensibilidad, su ethos. Vezzetti advierte que la posibilidad de revisar y discutir la violencia revolucionaria (especialmente en torno a Montoneros, en su caso) responde a un nuevo régimen de memoria que permite indagar otras representaciones que rebasan a la figura de víctima, como las del traidor, el héroe o el mártir. Desde la década del noventa, nuevas voces intervienen en la reflexión en torno a la violencia de los setenta para recuperar la experiencia de la revolución y de la lucha armada en un nuevo escenario de enunciación que debe asimilar la derrota. Nos interesa abordar, a partir de Roberto Bolaño, algunos de los motivos que articulan los relatos de la revolución que pueden ser leídos en diversas claves, sea en el empeño por sostener un objetivo de transformación o en ese "terreno afectivo de la posdictadura" (Avelar 87) que conjuga el trauma, el duelo o la melancolía, las aristas de la derrota. En la literatura, la articulación entre lo sagrado y la experiencia revolucionaria adquiere nuevos contornos para interpelar tanto las muertes del pasado reciente como los silencios impunes de un presente crepuscular.

\section{RELATOS DE LA JUVENTUD SACRIFICADA}

El motivo más reproducido sobre la experiencia revolucionaria de los setenta es aquel que entrona una generación de jóvenes latinoamericanos cuyos ideales de solidaridad los llevaron a emprender una aventura abnegada por un mundo mejor. El tópico del idealismo de los fines silencia un proyecto, un método y una cultura de la violencia y al mismo tiempo desplaza algo tan difícil de procesar como la muerte (Vezzetti 97-100). La relación con la muerte configura diversos mitos que han construido la figura del guerrero revolucionario a partir de la convergencia entre el sacrificio y el 
coraje. De matriz cristiana, la configuración de una "ética de la revolución" traza la conducta ejemplar del guerrero cuyo paradigma es el combatiente que ofrece su vida por la causa colectiva. Esta ética está regida por los rigores de la lucha clandestina y arma una red de valores asociados al sacrificio y al ascetismo. ${ }^{1}$ También puede entroncarse con la tradición aristocrática de raíces griegas en torno a la muerte bella en la que el héroe muerto en combate constituye el glorioso destino ante el mandato cívico de morir por la patria.

La sacralidad de la experiencia que, en los setenta, articulan el imaginario religioso con una "moral del guerrero" aparecen en la contundente "Carta a mis amigos" de Rodolfo Walsh. El recuerdo de su hija Victoria y la reflexión ante su muerte provocan un texto breve y conmovedor que hilvana los tópicos de la lucha armada sobre el despojo místico, la voluntad de acción y la entrega sacrificial a una causa común. El contexto en el que Walsh imagina el final de Vicki permite correrse del panegírico lacrimógeno por la juventud perdida en tanto la decisión razonada y urgente de lucha responde a un "sentido del deber" como el de "tantos muchachos que repentinamente se volvieron adultos" (244). ${ }^{2}$ Sin embargo, la sensibilidad de padre-y escritor-se filtra en la retórica testimonial cuando se detiene en el camisón blanco y desproporcionado, en la risa provocada por la novedad de la Halcón o en la imagen que cifra el vacío y el horror -el punctum barthesiano del diminutivo atroz-: "Encontraron una nena de algo más de un año, sentadita en una cama, y cinco cadáveres" (246). Esa imagen se une violentamente con la actitud previa de la madre que elige el propio disparo "como una última victoria sobre la barbarie" (245) y permite el pasaje de la muerte a la vida: la nieta de Walsh introduce el desplazamiento de la muerte del mártir hacia la vida de los otros. Victoria "no vivió para ella, vivió para otros" pero "su muerte fue gloriosamente suya" (246) y Walsh la asume como propia aun cuando renacer implique allí un camino sin retorno. Es por ello que el militante regresa al escritor apelando a la supervivencia de la palabra, "esto es lo que quería decir a mis amigos y lo que desearía que ellos transmitieran" (246) en el pasaje inverso de la encarnación, en el que va de la muerte a la resurrección en la palabra. ${ }^{3}$

1 Junto con el trabajo de Vezzetti sobre el caso argentino, puede leerse el texto de Sergio Ramírez donde, en otro tono y para otro contexto, recupera la memoria de los mártires de la revolución sandinista ("como los santos") y reflexiona sobre la derrota a partir de un "exceso de muerte".

2 La prosa de Horacio González bien resume esta actitud: "La idea de una 'lúcida muerte' se sitúa muy cercana a una hagiografía martirológica. De algún modo, el largo aliento de un cristianismo sacrificial se infunde en esta oración walshiana. Y se pone a esa muerte como una ofrenda plena de justicia, con una vocación de entrega hacia dimensiones colectivas de contornos sagrados y con detalles laicos de una lucha guerrillera que de todos modos suponía mártires dispuestos a una fusión mística con esos otros 'millones' que eran el alma de la comunidad reivindicante” (González 158).

3 Remitimos al texto de Julián Axat sobre las cartas de Walsh, donde busca al poeta que no supo era poeta: "Walsh es como el Ángelus Novus, parado frente a las cenizas de la Historia nacido desde las cenizas de

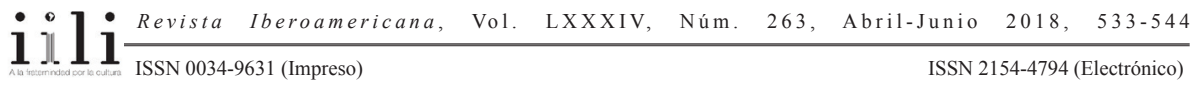


Una vez instalada la derrota de la izquierda latinoamericana ante el horizonte desolador trazado por el terrorismo de Estado contrarrevolucionario (en América Central, por ejemplo) y el plan sistemático de muerte de las dictaduras (en el Cono Sur) el tópico de la juventud revolucionaria sacrificada encarna en diversos relatos con implicancias estéticas y éticas diferentes. Se trata de "escrituras de la derrota" que ante las nuevas condiciones enunciativas asedian los saberes, las memorias y olvidos del pasado reciente para configurar distintas evaluaciones políticas y culturales desde un presente signado por la pérdida del sentido, la fractura de las certezas, la caída de las utopías (Amar Sánchez y Basile 327-50). En este nuevo escenario, la narrativa de Roberto Bolaño puede leerse como, con palabras del mismo autor, una carta de amor y de despedida de los ideales de aquellos jóvenes, "de las hazañas heroicas de una generación entera de jóvenes latinoamericanos sacrificados” (Amuleto 54).

Es interesante sondear el modo en que esa generación latinoamericana de jóvenes homenajeados insistentemente aparece en la obra de Bolaño, en Los detectives salvajes (1998) o en el final de Amuleto (1999), por ejemplo, en el camino que une la poesía con la lucha, la utopía y el horror. Un homenaje-deuda que evita reproducir el paradigma de la desilusión o la figura del guerrillero arrepentido (Beverley 167), pero que insiste en incorporar la derrota a partir de la pregunta por la muerte y la imposibilidad de olvidar el costo humano de la revolución. En Amuleto la voz de Auxilio asume la autoridad como narradora lejos de la claridad y la transparencia de quien debe testimoniar y deja fluir un relato anclado en el trauma que dilata, que deja una historia pendiente, a la deriva, para retomarla de vez en cuando y contarla al final: es la historia de los jóvenes latinoamericanos que "caminaban indefectiblemente hacia el abismo" (152).

Contra el protocolo genérico del testimonio en tanto elemento de prueba para establecer una verdad a contrapelo de la historia oficial, contra la voz de los vencidos que, como sostiene Avelar, no han incorporado una reflexión sobre la derrota y retoman el discurso de una resistencia heroica, Bolaño coloca en primer plano la masacre de jóvenes latinoamericanos: “[...] estúpidos y generosos [...] que todo lo entregan y no piden nada a cambio, y ahora de esos jóvenes ya no queda nada [...] Toda Latinoamérica está sembrada con los huesos de éstos jóvenes olvidados" ("Discurso de Caracas" 37). Sin panegíricos ni mitologías, la escritura encarna una generación que entregó su juventud a favor de una causa ${ }^{4} \sin$ abultar la epopeya subjetiva de la nostalgia

su hija; él tiene la certeza que nunca podría sobrevivir a su hija, se siente condenado aun cuando pueda extender o proyectar su permanencia en el mundo, ya no como militante o escritor, sino como hombre. La carta a Vicki ensaya un dialogo con los muertos y es anticipatorio, a través de la alucinación revela su propio final. El 'Ustedes no nos matan, nosotros elegimos morir', más allá de la idea de versiones contrapuestas o abiertas, yo la entiendo como parte de una necesaria creencia para poder sostener su despedida, y no como acto de especulación en la fundación del propio mito".

4 “.... luchamos a brazo partido, pero tuvimos jefes corruptos, líderes cobardes, un aparato de propaganda que era peor que una leprosería, luchamos por partidos que de haber vencido nos habrían enviado de

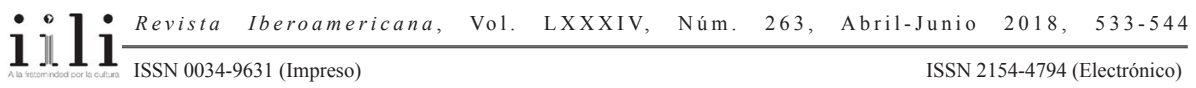


por un pasado con sueños de utopía. Por el contrario, insistir en una muerte oscura y abisal despoja al relato de la sacralización de la violencia y del mito de la muerte purificadora. Amuleto devela los abismos de la utopía en un presente elegíaco desde el que la potente complejidad de la narrativa de Bolaño se erige, ajena al lagrimeo simplificador de ciertas visiones idílicas y despolitizadas de vencedores y derrotados (Amar Sánchez 173-203). No tan lejos de Walsh, Bolaño busca menos al héroe que a la sombra, al fantasma que asedia su escritura, esa generación de la que queda el canto, el amuleto, encarnado en un relato que los evoca desde la melancolía, el trauma y el recuerdo, siempre perturbador.

\section{El RELATO DEL MAL ABSOLUTO}

Bolaño ensaya otro modo de desandar el pasado reciente latinoamericano, ya no desde la revolución sino desde la violencia extrema de las dictaduras a partir de la articulación de lo sagrado, el horror y el arte. En Estrella distante (1996) recupera el ethos revolucionario desde su envés horroroso: la compleja y huidiza figura de Carlos Wieder, quien asume y se entrega de lleno a la instauración de un nuevo orden a partir del arte. La transformación político-social queda relegada en segundo plano ante el proyecto de este artista del mal que recoloca la sacralidad del arte ligado a lo trascendental en las fauces de la violencia. Si bien esta vanguardia del mal sólo es viable en un contexto represivo y criminal (del que Wieder forma parte activa) la transgresión radical del poeta no es solo ligar arte y muerte sino anunciarlo, hacer visible lo que debe permanecer oculto y buscar la imagen de aquello que no tiene imagen, de lo que no hay experiencia posible: la muerte.

Más allá de la "co-pertenencia” del vanguardismo estético y los dispositivos tecnomilitares (Villalobos-Ruminott) -neovanguardia y dictadura-que muchos críticos han señalado, Bolaño escenifica una crítica de la violencia desde una particular concepción del arte por fuera de todo mesianismo político o estético. La novela comienza en los talleres de poesía que proliferan durante el gobierno de Salvador Allende y que sistemáticamente serán desarticulados con la dictadura. Aquí, la fuerte presencia del narrador apela a la verdad del testigo: yo estuve ahí, yo sé lo que aconteció. Así, se constituye lo testimonial a partir del yo narrador "Bolaño" que da cuenta de la experiencia de la violencia que sufrió toda una generación, la suya, ante la derrota revolucionaria poniendo el foco sobre todo en la destrucción de la poesía. Sin embargo, la novela no se estanca en el racconto de la aniquilación generacional, sino que exige explorar zonas más complejas. La figura de Carlos Wieder es la puerta de entrada a

inmediato a un campo de trabajos forzados, luchamos y pusimos toda nuestra generosidad en un ideal que hacía más de cincuenta años que estaba muerto". (Bolaño, "Discurso de Caracas" 37). 
esos agujeros que permiten abordar otras aristas de la violencia a partir del mal como proyecto artístico. Wieder es ante todo "un artista del mal", es un poeta que instala una voluntad del arte a través de la muerte. Si bien forma parte del grupo, Alberto Ruiz-Tagle (identidad de Carlos Wieder durante la época de los talleres literarios) se recorta del fondo común, ${ }^{5}$ se singulariza con la marca del enigma: "Nadie lo conocía" (Estrella distante 22), adquiere un halo sagrado que expresa un núcleo oculto al cual no se puede acceder, nadie puede ver lo que realmente se mueve detrás (sólo la Gorda Posadas quien intensifica el secreto) (22). ${ }^{6}$

Carlos Wieder es ante todo un poeta que no manifiesta tanto una fascinación por el mal como la voluntad de hacerlo y, sobre todo, crearlo a partir del arte. La novela narra dos intervenciones artísticas de Wieder (los vuelos y la muestra de fotos) que lo colocan en la escena vanguardista del arte en tiempos violentos. Importa tanto el gesto rupturista que pareciera encarnar como el escenario que lo enmarca, pero creemos que no se trata sólo de la complicidad del artista con el poder, sino de la utilidad del poder que hace el artista. Si bien es parte del aparato represivo de la dictadura, parece antes que todo utilizar el contexto del terror para ejecutar su arte. Es un artista del terror y se erige por lo tanto como contrario a la "banalidad del mal". Wieder no es un mero engranaje de la burocracia dictatorial, sino que se coloca como el poeta-sacerdote que cabalmente asume un proyecto macabro, el cual defiende ante todo riesgo. Es por ello que realiza los vuelos aún ante las inclemencias del tiempo y no le interesan los conflictos que puede provocar la muestra fotográfica ante los altos mandos militares - para quienes Wieder constituye un peligro: el de mostrar la cara oculta del régimen-.

Su primera presentación en el mundo encorsetado del arte son los poemas escritos en el aire desde una avión piloteado por él mismo (es teniente de la Fuerza Aérea de Chile) y parece encajar perfectamente dentro del denominado retorno a las vanguardias de modo que cumple con el mandato de la superación de las limitaciones de la institución artística, por ejemplo, al disolver los marcos genéricos y ampliar los formatos establecidos de la poesía. La fusión entre estética y cotidianeidad también se actualiza en la ampliación de los canales de recepción de la obra. ${ }^{7}$ Ahora bien, su primera acción

Los jóvenes hablan según sus filiaciones políticas, viven con sus padres, carecen de dinero; mientras que Ruiz-Tagle parece fuera del tiempo, utiliza un español de ciertos lugares que parecen detenidos, vive solo, nunca le faltó el dinero (16). Es como si la distancia entre ellos intensificara, en los años previos al horror, los diferentes caminos que tomarán los personajes durante (y después) de la dictadura. Esto se anticipa en la visita de Bibiano O'Ryan a la casa de Ruiz-Tagle que, bajo la comparación con una escena de la película El bebé de Rosemary, apunta a lo inefable demoníaco pero "presente, tangible", el horror que mostrarán las fotografías también se anuncia cuando esa falta (lo que no puede decirse pero está) se describe como "si el anfitrión hubiera amputado trozos de su vivienda" (17).

6 Los rasgos de Wieder revisten la ambigüedad de lo sagrado, tanto en la fascinación que ejercía sobre el grupo como en su presencia oscura e impenetrable (Agamben, Homo Sacer I 98-105).

7 El resumen de los rasgos neovanguardistas los enumera Nelly Richard (La insubordinación 42-50)

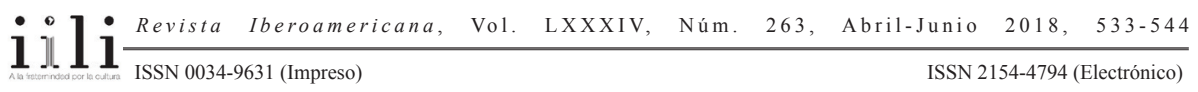


poética es presenciada por algunos presos (sólo uno reconoce y entiende el latín de los escritos en el aire: el loco Norberto que espera una nueva guerra mundial, otros creen que es publicidad de la iglesia) y es reconocida - pero incomprendida- por "soldados" y "caballeros" (20). El elitismo dado por la incapacidad del público para comprender la obra y la ruptura formal de la intervención artística resumen el acto vanguardista que parece estar matizado por el complejo vínculo con el poder que Wieder establece. Sus vuelos artísticos son disfrutados por "altos oficiales" y "hombres de negocios" en actos y conmemoraciones, alejándose de cualquier idea tradicional de vanguardia, ${ }^{8}$ legitimado por la crítica conservadora (el "anticuario y católico" (45) Nicasio Ibacache, quien se perfila magistralmente en Nocturno de Chile).

El contenido de sus escritos en el aire muchas veces parecería promulgar la violencia de su entorno de modo que la fusión arte y vida se transforma en arte y muerte ya que los nombres femeninos que dibuja en el aire corresponden a las mujeres desaparecidas y asesinadas. El proyecto vanguardista de Wieder actualiza el discurso genesíaco que articula lo sagrado con la identidad del artista. La instauración de un nuevo orden, a partir del génesis bíblico revisitado cuya figura central y superior es el artista que firma el texto, impone la centralidad de la muerte -como limpieza-que no sólo implica la muerte de mujeres sino de la poesía (son poetas asesinadas). La única voz que se distancia de la euforia que provoca Wieder es la del narrador quien resume la obra en el cielo con una palabra: incoherencia (91) y más tarde sentenciará que Wieder no es un poeta sino un criminal (126).

Para sondar cómo el mal se introduce en la esencia del arte, Georges Bataille, antes que describir sus manifestaciones, arma una constelación de figuras cuyo arte convoca la muerte, el mal o la violencia con el fin de despojarse de los límites insoportables de la vida. Sólo la literatura puede desnudar la transgresión de la ley y quebrar el principio vital que aleja al ser humano de la región de la muerte (99). Cuando indaga la fascinación por el mal que Charles Baudelaire advierte que el poeta no participa de él, dice casi con Kant que no tiene la voluntad del mal (92). Wieder no podría compartir

cuando describe las acciones que la "avanzada" realiza en el Chile dictatorial. No está de más recordar aquí las intervenciones de Rául Zurita en el desierto de Atacama (recordar a Willy Schürholz en La literatura nazi en América, discípulo de Ramírez Hoffman/Ruiz-Tagle/Wieder) o sus Escritos en el cielo. Al respecto ver (entre otros): Chiara Bolognese (Anales 259-272). Si insistimos en localizar la novela de Bolaño, también resuena la fotografía de Eugenio Dittborn ("Fosa común”), que Richard lee desde un descentramiento de la foto a partir de la retórica militar y criminal: "detención", "captura", "prisión del encuadre" (La insubordinación 20) y que Wieder llevará al extremo, literalmente. Ver el detenido análisis de Ina Jennerjahn ("Escritos” 69-86).

8 Ana Longoni es quien relee la teoría de Peter Bürger como "encorsetamiento" a la vanguardia al limitar las aproximaciones concretas, específicas ("La teoría..." 61-68). Aquí Wieder encarnaría una vanguardia despojada de algunos de sus dogmas: como la idea de lo colectivo y el impulso de resistencia y ruptura con el poder (institucional-político, estético). 
las páginas de Bataille sobre Brönte, Kafka o Blake porque él mismo encarna el mal que el filósofo francés quiere leer en la literatura. Una de la percepciones recurrentes del narrador sobre Wieder describe una "voluntad sin fisuras" (53), incluso antes del encuentro final con Abel Romero parece "más dueño de sí mismo" (153) que ninguno. De modo que este vanguardista del mal transgrede todo límite porque él mismo encarna la voluntad macabra de ejercer la violencia radical del ser humano al prójimo.

La última obra en público de Wieder ya no "representa" a las mujeres asesinadas, ahora las fotografía, es decir las "presenta" conforme a una voluntad artística de lo obsceno cuyo objetivo es exhibir la muerte. Las muertas de Wieder son las muertas del poder y todos callan y lavan culpas cuando encierran al crimen en los confines del arte y al mismo tiempo el servicio de Inteligencia rápidamente oculta el "arte" de Wieder en una caja. ${ }^{9}$ El proyecto de Wieder reviste un vínculo extremo entre el arte y el mal pues no se trata simplemente de reflejar lo real en las fotografías, sino de hacer arte a partir del acontecimiento de la muerte. Esta pulsión artística que constituye la obra de Wieder se circunscribe al asesinato (como un testigo de la exhibición, Muñoz Cano, puede inferir: es el crimen en tiempo real, las mujeres son fotografiadas en el instante fugaz entre la tortura y la muerte); lo que nos lleva a ligar su "estética" con el género de las snuff movies ${ }^{10}$ al instalar la muerte como espectáculo en la exposición montada en el cuarto cerrado. La voluntad de unir arte y muerte es llevada al punto último con la intención de dar cuenta del momento único e irrepetible en el que dos extremos -la vida y la muerte- se tocan. ${ }^{11}$ Wieder procura captar con sus fotografías el instante mismo en que las víctimas se mueren y ese acontecimiento captado por la lente fotográfica y la experiencia que provoca en el espectador están signados por un horror que se intensifica con la presencia del artista en la obra. Sabemos que Wieder está detrás de cada escena (como lo está y se percibe detrás de cámara en las películas pornográficas).

9 Wieder sigue la lógica contraria a Enriquito, asesino de Pizarro, ambos protagonistas del relato intercalado que Abel Romero cuenta al narrador. Enriquito intenta disipar las sospechas en su contra a partir de "revestir el crimen con los ropajes de la maravilla y de lo inverosímil" (123), volviéndolo ficción, interviniéndolo, montando un escena; mientras que Wieder asume el riesgo de mostrar, de exhibir.

10 Anna Topczewska analiza la articulación de las snuff movies con "La parte de los crímenes" en 2666 (2004) ("La parte"). Seguimos con atención su artículo pues algunos de sus argumentos son aplicables a Estrella distante. Topczewska señala que la especificidad de la snuff movie reside en la relación que establece con lo real antes que con lo macabro, que se da por sentado. Sin embargo, creemos que Estrella distante invierte esta idea porque Wieder no se plantea representar "lo real" (eso no tiene mayores complicaciones), sino que su interés radica en presentar el instante mismo de la muerte que excede cualquier noción de lo real en tanto la realidad se detiene en el momento en que la lente dispara, transgrediendo el acontecimiento único que está por fuera de toda representación.

11 Muñoz Cano advierte que si bien las mujeres fotografiadas parecen maniquíes es probable que aún estuvieran vivas en el momento de hacerles la instantánea (97).

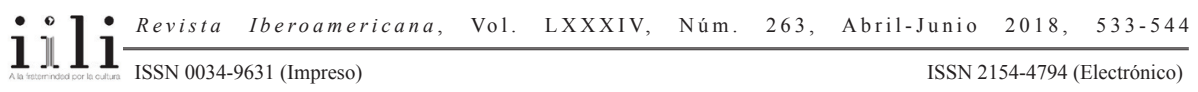


No se trata del artista que observa la foto de la muerte y a partir de allí estetiza el dolor, lo abyecto, ${ }^{12}$ sino que se trata de su voluntad asesina trasformada en arte a partir de un plan que articula arte y muerte en la esfera de lo sagrado. Ya no estamos ante "la muerte bella" de quien se sacrifica por un ideal colectivo; se trata del "hórrido morir" de los asesinados, de "los cuerpos prisioneros como materias despojadas de nombre, de dolor, de memoria y de destino" (González 155). Tampoco estamos ante el valor de la vida avocada a los otros, sino ante la nuda vida, la mera corporalidad sin sentido, desechable. Pero, a diferencia del homo sacer de Agamben, "a quien cualquiera puede dar muerte pero que es a la vez insacrificable" (18), Wieder no sale de la esfera del sacrificio porque sostiene la ambivalencia de lo sagrado en tanto pretende fundar una comunidad (artística, de vanguardia) que exige el derramamiento de sangre para preservarla.

La relación entre lo sagrado y la violencia que René Girard rastrea en las sociedades primitivas vuelve resignificada en el proyecto artístico de Wieder. La violencia sagrada refiere el crimen originario que se instaura como origen de la comunidad (un nuevo orden anunciado en los vuelos que humean el Génesis, ligado a la muerte como limpieza y resurrección). El sacrificio desvía una violencia futura a partir de que la víctima asume en sí misma, en tanto ofrenda, el castigo colectivo. La extrapolación del análisis de Girard al contexto devastador de las dictaduras y totalitarismos donde (cual sociedad arcaica) no hay un sistema legal que desvíe la violencia (hacia el "chivo expiatorio") 13 sino que la instaura, permite aproximarse a Wieder en su ambigua oscuridad para indagar los oscuros senderos de la violencia latinoamericana en las últimas décadas.

Al instituir su arte en el orden de lo sagrado configura la instancia sacrificial a partir de la violencia que coloca a la víctima en el lugar del chivo expiatorio. Wieder asume la función sacerdotal del poeta dado a fundar, a dar origen a un nuevo orden que es un arte nuevo a través del sacrificio (recordemos el ascetismo extraño con que se lo percibía en tiempos de los talleres literarios) de mujeres poetas. El giro a la sacralidad del mal de este artista de la violencia y asesino del poder no evita la violencia sino que la perpetra, la establece y, aún más, la escenifica: la vuelve espectáculo (Imbert 32). En clave girardiana, el proyecto de Wieder se enmarca en la restauración de una religiosidad del mal que lejos de aplacarla solo puede conducir a una violencia desenfrenada. ${ }^{14}$

${ }^{12}$ Como la foto del torturado chino que Salvador Elizondo encuentra en el libro de Georges Bataille (Las lágrimas de Eros) y da origen a Farabeuf.

13 "Es concebible que una víctima aparezca como responsable de las desdichas públicas y eso es lo que ocurre en los mitos, al igual que en las persecuciones colectivas, pero la diferencia reside en que exclusivamente en los mitos esa misma víctima devuelve el orden, lo simboliza e incluso lo encarna" (Girard 60).

${ }^{14}$ George Bataille advierte: "si lo sagrado, la totalidad de la plenitud del ser se le escapa al hombre, ya no sería más que un hombre incompleto; pero lo sagrado, cuando adquiere la forma de la guerra lo amenaza con la aniquilación total" (La felicidad 170).

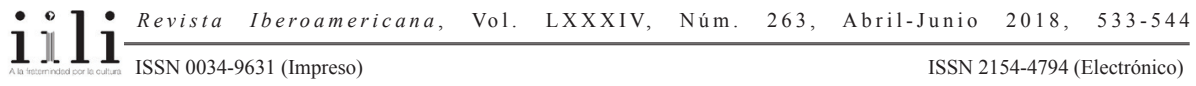


De este modo, Wieder articula una genealogía del terror y del nuevo orden que se remonta a las bases del cristianismo y que también ha sido recuperada por los discursos mesiánicos de la izquierda y por los tópicos fundamentales de la derecha fascista. Hugo Vezzetti abarca estas cuestiones en un riguroso análisis donde refiere cómo estos sistemas ideológicos y de acción política proponen una regeneración basada en hacer tabla rasa con el pasado (176) y -desde los jacobinos- el terror se organiza como dispositivo instrumental. El afán que persigue Wieder de instaurar un orden nuevo, afín a la sensibilidad revolucionaria de la vanguardia, requiere una ruptura con el pasado que implica la aniquilación: la limpieza, la muerte (tal como anuncia en sus vuelos infernales).

Si está claro que la carrera de Wieder demuestra que el arte de vanguardia y la violencia estatal no están reñidos (86), su radicalidad estriba en la posición del artista respecto del mal con el que se enfrenta, perpetra y anuncia. No importa tanto la calidad de la obra de Wieder como la fascinación y el terror que provoca en los demás, y la voluntad y el propio placer que experimenta sobre todo durante la exposición de fotos. ${ }^{15}$ Wieder se detiene en la estetización del mal transgrediendo el límite de la representación que se constituye en una opción válida al mismo tiempo que deja de serlo en la medida en que él mismo es el ejecutor del mal. Ya no hay poesía, sólo crimen (reiteramos, la mayoría de las mujeres aniquiladas son poetas) de modo que la estética del mal promulgada por Wieder hace sistema con el proyecto exterminador de la dictadura que, como asume la novela en tanto voz generacional, no sólo persiguió y destruyó a sindicatos, a movimientos políticos sino también a la poesía.

Aquí se abre otra aproximación al mal anclada en los crímenes de la historia de los que Wieder es responsable y que la novela intenta recuperar sin por ello desplazar el núcleo oscuro del texto (Wieder y el mal) hacia una salida fácil de condena y denuncia contra los crímenes del Estado y los muertos de la izquierda. La desacralización de la experiencia revolucionaria tiene su espejo atroz en la desacralización del arte cifrado en el insostenible proyecto macabro de Wieder. Cuando lo sagrado roza lo abyecto sobre la base del terror se abre esa grieta perversa al servicio de la muerte en un escenario donde los sujetos son irrelevantes, prescindibles y solo es posible tejer redes de "solidaridad" a partir de la complicidad, el delito y la corrupción (Mier 19).

Como ya mencionamos, el personaje de Wieder no encaja en la figura de Hannah Arendt sobre la "banalidad del mal" porque los engranajes de la violencia estatal sólo le sirven a su proyecto artístico que se constituye en sí mismo como maquinaria del horror. Tampoco se trata de la grandeza satánica ni de la tentación por sondar las zonas ocultas del ser, sino que se muestra en su estado más extremo, en la frialdad consciente del crimen autorizado que sirve además para un proyecto artístico que fracasa. Wieder

15 A medida que el público sale de la habitación, Wieder sonríe “cada vez más satisfecho” (96).

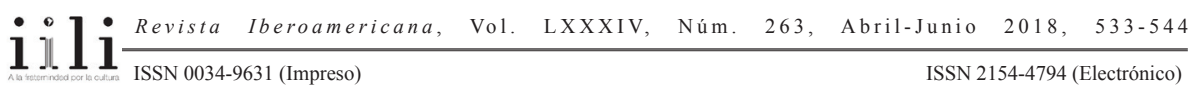


no es la estrella más brillante, sino la que cae y debe invisibilizarse hasta desaparecer. A medio camino entre el intento de comprender el mal y la imposibilidad de hacerlo, en modo alguno se plantea una dicotomía cerrada y el mismo narrador lo reconoce: "Wieder y yo habíamos viajado en el mismo barco, sólo que él había contribuido a hundirlo y yo había hecho poco o nada para evitarlo" (131). Además, a pesar de colaborar con Abel Romero, detective justiciero y asesino a sueldo, el narrador expresa su disconformidad con el desenlace que el detective ha venido a ejecutar. ${ }^{16}$ Abel Romero será el asesino a sueldo de Wieder y se debate entre dos posibilidades que ponen en jaque el lugar de lo sagrado al mismo tiempo que denuncian las imbricadas relaciones entre violencia y derecho. Una, involucra la justicia por mano propia en donde la colaboración del escritor es clave y que se ejercita bajo la ausencia estatal de acciones reparadoras frente a la violencia dictatorial. Otra, asume la crítica a la venganza individual a través de la resistencia que el narrador atisba frente al acto final. En esta dualidad del personaje "Bolaño", tensada entre su colaboración con Abel y su rechazo a la muerte del criminal, se articula una compleja postura respecto de la justicia y los modos de ejercerla, respecto del eterno retorno de la violencia devenida venganza. ${ }^{17}$ Pero sobre todo constituye un original modo de explorar ciertos nudos significativos de las derrotas de la izquierda revolucionaria; revisar sus macronarrativas; interpelar sus herencias en el presente, lejos de la utopía, ajeno al motivo de la solidaridad, el sacrificio o el coraje.

\section{BIBLIOGRAFÍA}

Agamben, Giorgio. Homo Sacer I. El poder soberano y la nuda vida. Valencia: PreTextos, 2003. Profanaciones. Buenos Aires: Adriana Hidalgo, 2005.

Aguilar, Paula. "El policial en la posdictadura chilena: una relectura de El Tercer Reich de Roberto Bolaño". Memorias en tinta. Ensayos sobre la representación de la

${ }_{16}$ Abel Romero forma parte del "Epílogo de monstruos" que cierra La literatura nazi en América (1996), junto con otros infames y con un tal Juan Cherniakovski, "guerrillero panamericano" (205). El crimen de Romero tiene que ver con la justicia y también con la venganza, lo que pareciera explicar su inclusión en el epílogo. Igualmente la aparición en la lista infame del director del taller de poesía al que Wieder asiste, Juan Stein (sobrino de Iván Cherniakovski, un general del Ejército Rojo) apunta a los crímenes en nombre de la causa revolucionaria. La pauta está en Estrella distante cuando el narrador relata la biografía de Stein y evoca la figura ya clásica de la traición de la izquierda latinoamericana: "los hijos de puta que mataron a Roque Dalton mientras dormía para cerrar la discusión y porque así convenía a su revolución" (69). Pero no se trata de equiparar crímenes sino de abismarse en su sin sentido, de visibilizarlos con la mirada microscópica de la literatura que todo lo desestabiliza.

17 Esta cuestión volverá a aparecer en El Tercer Reich (2014). También regresa dimensionada de un modo completamente distinto en 2666 en la historia de Hans Reiter y Leo Sammer (aquí sí aparece la banalidad del mal, en el nazismo precisamente).

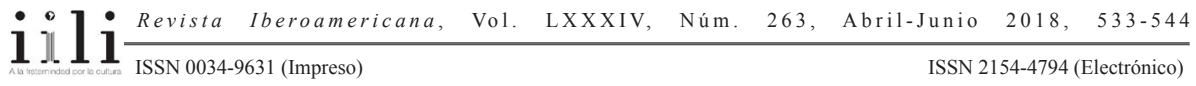


violencia politica en Argentina, Chile y Perú. Lucero De Vivanco, ed. Santiago: Ediciones de la Universidad Alberto Hurtado, 2013.

Amar Sánchez, Ana María. Instrucciones para la derrota. Narrativas éticas y políticas de perdedores. Barcelona: Anthropos, 2010.

y Teresa Basile. "Derrota, melancolía y desarme en la literatura latinoamericana de las últimas décadas”. Revista Iberoamericana LXXX/247 (Abril-Junio, 2014): 327-350.

Avelar, Idelber. Alegorías de la derrota: la ficción posdictatorial y el trabajo del duelo. Santiago de Chile: Editorial Cuarto Propio, 2000.

Axat, Julián. "Cartas de Rodolfo Walsh, diez pistas desde una búsqueda poética”. La Tecl@Eñe Revista Digital de Cultura y Politica. Ideas, cultura y otras historias XIII/63 (2014).

Barthes, Roland. La cámara lúcida. Barcelona: Paidós, 1989.

Bataille, George. El Estado y el problema del fascismo. Valencia: Pre-Textos, 1993. La literatura y el mal. Ediciones elaleph.com, 2000.

"La guerra y la filosofía de lo sagrado". La felicidad, el erotismo y la literatura. Buenos Aires: Adriana Hidalgo, 2001.

Benjamin, Walter. "Para una crítica de la violencia”. Iluminaciones IV. Madrid: Taurus, 1991.

Beverley, John. "Repensando la lucha armada en América Latina". Sociohistórica 28 (2011): 163-177.

Bolaño Roberto. Estrella distante. Barcelona: Anagrama, 1996. Amuleto. Barcelona: Anagrama, 1999.

"Discurso de Caracas (Venezuela)". Entreparéntesis. Barcelona:Anagrama, 2004.

Bolognese, Chiara. "Roberto Bolaño y Raúl Zurita: referencias cruzadas". Anales de Literatura Chilena 11/14 (2010): 259-272.

García, Jorge Tomás. "Una reflexión sobre lo bello y lo sublime en la bella muerte del guerrero espartano". Journal of Ancient Philosophy IV/2 (2010).

Girard, René. La violencia y lo sagrado. Barcelona: Anagrama, 1985.

González, Horacio. "Una imagen filmada de Azucena Villaflor: reflexiones sobre la muerte y el hórrido morir". Escritos en carbonilla: figuraciones, destinos, retratos. Buenos Aires: Colihue, 2006.

Imbert, Gérard. Los escenarios de la violencia. Barcelona: Icaria1, 1992.

Jennerjahn, Ina. "Escritos en el cielo y fotografías del infierno. Las "acciones de arte" de Carlos Ramírez Hoffman según Roberto Bolaño”. Revista de crítica literaria latinoamericana XXVIII/56 (2002): 69-86.

Logie, Ilse. "Mensonge romantique revisited: la vigencia actual de algunos conceptos de René Girard para la literatura". Revista Anthropos 213 (2007): 112-125.

Longoni, Ana. "La teoría de la vanguardia como corset". Pensamiento de los confines (18 julio 2006): 61-68.

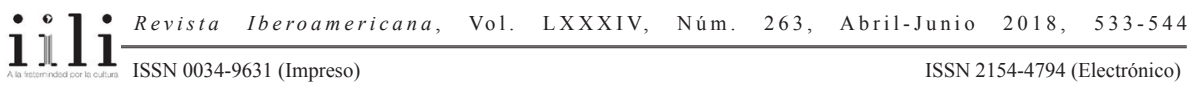


Mier, Raymundo. "Notas sobre la violencia: las figuras y el pensamiento de la discordia.

El acento antropológico: violencia, vínculo y norma”. Fractal 38 (2005).

Nancy Jean-Luc and Richard Livingston. "The Unsacrificeable". Literature and the Ethical Question Yale French Studies 79 (1991): 20-38.

Ramírez, Sergio. Adiós muchachos: Una memoria de la revolución sandinista. Madrid: Aguilar, 1999.

Richard, Nelly. La insubordinación de los signos. Santiago: Cuarto Propio, 1994. Topczewska, Ana. "La parte de los crímenes: Una snuff movie literaria”. VIII Congreso Internacional Orbis Tertius de Teoría y Crítica Literaria, 7 al 9 de mayo de 2012, La Plata.

Vezzetti Hugo. Sobre la violencia revolucionaria, memorias y olvidos. Buenos Aires: Siglo XXI, 2009.

Villalobos-Ruminott, Sergio. “A Kind of Hell: Roberto Bolaño and the Return of World Literature". Journal of Latin American Cultural Studies 2/18 (2009): 193-205.

Walsh, Rodolfo. "Carta a mis amigos". Ese hombre y otros papeles. Daniel Link, ed. Buenos Aires: Seix Barral, 1996. 